PRELIMINARY DEVELOPMENT OF

INSERVICE INSPECTION METHODS FOR LMFBR'S

By

J. C. Spanner

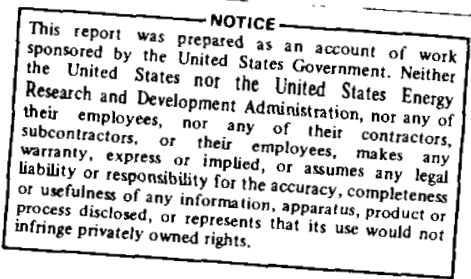

March 1976

This paper was prepared for presentation at the International Working Group on Fast Reactors (IWGFR) Specialists' Meeting on "Inservice Inspection and Monitoring of LMFBR's" in Bensberg, Federal Republic of Germany, March 9-12, 1976.

This paper is based on work performed by the Hanford Engineering Development Laboratory, Richland, Washington, operated by the Westinghouse Hanford Company, a subsidiary of Westinghouse Electric Corporation, under United States Energy Research and Development Administration Contract E(45-1)-2170.

Copyright License Notice: By acceptance of this paper, the pubiisher and/or recipient acknowledges the U.S. Government's right to retain a nonexclusive, royalty-free license in and to any copyright covering this paper. 


\section{DISCLAIMER}

This report was prepared as an account of work sponsored by an agency of the United States Government. Neither the United States Government nor any agency Thereof, nor any of their employees, makes any warranty, express or implied, or assumes any legal liability or responsibility for the accuracy, completeness, or usefulness of any information, apparatus, product, or process disclosed, or represents that its use would not infringe privately owned rights. Reference herein to any specific commercial product, process, or service by trade name, trademark, manufacturer, or otherwise does not necessarily constitute or imply its endorsement, recommendation, or favoring by the United States Government or any agency thereof. The views and opinions of authors expressed herein do not necessarily state or reflect those of the United States Government or any agency thereof. 


\section{DISCLAIMER}

Portions of this document may be illegible in electronic image products. Images are produced from the best available original document. 
HEDL -SA-1092

Rev. 1

\title{
PRELIMINARY DEVELOPMENT OF \\ INSERVICE INSPECTION METHODS FOR LMFBR'S
}

\author{
J. C. Spanner
}

\section{ABSTRACT}

Although firm requirements have not yet been established in the United States for Inservice fnspection of LMFBR's, some initial development work on potentially applicable nondestmuctive testing methods has been conducted by the Hanford Engineering Development Laboratory. This paper contains a synopsis of investigations conducted in each of the following areas:

- Ultrasonic exconination of austenitic stainless steel welds

- Electro-thermal NDT method for stainless steel components

- Eddy current methods for in-situ excomination of heat exchanger tubes

- Under-sodium viewing and ránging

Development activities and experimental results obtained to date in each of these areas are highlighted, along with conments on potential applicability for inservice inspection of LMFBR's. 
HEDL -SA-1092

Rev. 1

\title{
PRELIMINARY OEVELOPMENT OF INSERVICE INSPECTION METHODS FOR LMFBR'S
}

\author{
J. C. Spanner
}

\section{Introduction}

Although firm requirements have not yet been established in the United States for inservice inspection of LMFBR's, some initial development work on potentially applicable nondestructive testing (NDT) methods has been conducted by the Hanford Engineering Development Laboratory. This laboratory is operated by the Westinghouse Hanford Company for the U. S. Energy Research and Developmert Administration. Preliminary development work has been conducted in each of the following areas.

- Ultrasonic Examination of Austenitic Stainless Steel Welds

- Electro-Thermal NDT Method for Stainless Steel Components

- Eddy Current Methods for In-Situ Examination of Heat Exchanger Tubes

- Under-Sodium Viewing and Ranging

A synopsis of the investigations conducted in each of these four areas is presented in this paper, along with a discussion of the experimental results that have been obtained.

Ultrasonic Examination of Austenitic Stainless Steel Welds

Ultrasonic (UT) equipment and techniques are widely used for the examination of welds in carbon steel components. However, ultrasonic examination of comparable welds in austenitic stainless steel components using conventional equipment and techniques is generally less effective due to the significant increase in acoustic attenuation exhibited by these materials. Furthermore, large amplitude ultrasonic indications may occur in weld regions that are free of rejectable defects. The acoustic energy attenuation problem, combined with the false indications encountered during the examination of many austenitic stainless stee 1 welds, have emphasized the need to develop more effective ultrasonic methods to supplement the examination processes presently employed during the fabrication of stainless steel components, and for possible use during inservice inspection of LMFBR plants. 
We rave recently completed the initial phases of a program that was desigried to investigate this problem and develop viable solutions [1] ${ }^{1}$. Sixtyeigrt weld samples were acquired, cataloged, and subjected to a series of conventional ultrasonic and radiographic examination processes. Figure 1 illistrates the variety of weld samples that were accumulated. Most of these samples are remnants from weld process or welding operator qualifications; hence, are typical of the welding processes used during the fabrication of piping for the Fast Flux Test Facility (FFTF). Figure 2 shows three acoustic imace photographs that clearly illustrate the severe acoustic attenuation that may be encountered when attempting to penetrate an austenitic stainless steel weld with ultrasound. These photographs were obtained using a whitelight schlieren apparatus, a continuous-wave (CW) ultrasonic system operating at $2.25 \mathrm{MHz}$, and a welded, $1 / 4$ inch $(\sim 1 / 2 \mathrm{~cm}$ ) thick test block made from Typє 304 staintess steel.

Following the initial examination, selected samples were machined to provide coupons with flat, parallel surfaces, and these coupons were subjected to additional, and more detailed, radiographic and laboratory ultrasonic procedures. Numerous sites that produced ultrasonic indications were detected in these coupons, and many of these noise sites were precisely located, ultrasonically characterized, and metallographically examined along planes in front of, through, and behind the noise site. In addition, montages of photomicrographs from the metallographic examination were assembled in the vicinity of 13 suspected noise sites to provide a broader pictorial perspective of the areas being analyzed. The most prevelant microstructures visible on the photomicrographic montages were: (1) weld-metal/base-metal interfaces, (2) homogenous-dendritic structure interfaces, and (3) parallel dendritic growth patterns located at, or adjacent to, suspected noise sites. It was determined that although the ultrasonic noise signals could usually be associated with major dendritic growth patterns, the existence and magnitude of some of the observed signals could not be explained simply on the basis of a dendritic microstructure.

Examples to illustrate the preceeding discussion are shown in Figures 3,4 , and 5. Figures 3 and 4 are photomicrographs of two noise sites in the same coupon that produced ultrasonic signals of significant amplitude. These

\footnotetext{
Numsers in brackets refer to references at the end of this paper.
} 
montages cover an area that contains some base metal and successive weld passes. The montage shown in Figure 5 covers a similar area in a noise free coupon. The apparent differences between the "noisy" weld and the noise-free weld appear to be restricted to the minor dendritic growth patterns present in the weld metal (upper) regions shown in Figures 3 and 4. Furthermore, the area shown in Figure 3 produced a greater reflected signal amplitude (45 percent) than the region shown in Figure 4 (35 percent), although the dendritic pattern is far more pronounced in Figure 4. This indicates that, although dendritic growth patterns may act as reflecting surfaces to produce ultrasonic indications, the levels and severity of the Jbserved noise signals cannot be directly correlated with relative quantities of dendritic microstructure.

3ased on experimental results obtained to date on this program, combined with the resuits reported by other investigators who are working on this and similar problems, it is concluded that the difficulties that are presently zncountered during ultrasonic examination of austenitic steel welds are generally attributable to the conditions delineated below. These may occur singly or in combination:

- Unpredictable and potentially severe attenuation of acoustic energy within the cast microstructures found in weldments.

- Sound beani refraction occurring at the weld/parent interface, within the weld, or both; and attributable to variations in acoustic velocities, internal stresses, etc. Such refraction effects cause the sound beam to bend; hence, the UT operator provides incorrect defect location data based on an assumption of straight beam paths. The consequences are that destructive exploration fails to reveal a defect at the predicted location, and the existence of an actual defect is not disclosed. Furthermore, the signal from an actual defect is incorrectly evaluated as a "spurious noise signal" which further errodes confidence in the reliability of ultrasonics as an effective examination method.

1 Reflections from microstructural discontinuities such as dendritic crystal growth, segregation of impurities at grain boundaries, etc. 
- Reflections from geometric discontinuities. These may be due to weld design configuration, weld root configuration, weld reinforcement, or ripple and shrinkage on the final weld surfaces.

- $\quad$ ther as yet undefined reflection and diffraction sources such as stress distributions or crystallographic orientations that produce wave front interferences.

Although we consider the problems that are presently encountered in examining austenitic stainless steel welds to be significant and difficult, we are confident that improvements can be achieved toward providing more effective nethods for ultrasonically examining this type of weld. Future efforts on this program will emphasize investigations of electronic signal enhancement. processes and computerized noise discrimination techniques, in conjunction with the development and evaluation of equipment, techniques, and procedures that are tailored to the examination of austenitic stainless steel weldments.

\section{E.lectro-Thermal NDT Method for Stainless Steel Components}

The infrared electro-thermal concept offers attractive potential as an alterrate method for examining austenitic stainless steel components. In principle, this method consists of passing a short, high-amplitude electrical current fiulse through a test object, and monitoring the resulting surface temperature profiles using a scanning infrared camera or similar sensing device. This relatively new NDT method responds to, hence is affected by, a somewhat different set of material characteristics than are the more common NDT methods. Thus, the electro-thermal method offers a possible alternative for examining stainless steel welds where microstructural or surface condition variations inhibit the effectiveness of the eddy current. (ET) and uitrasonic (UT) methods. The electro-thermal method also appears potentially applicable for inservice inspection of LMFBR components.

We have recently completed a preliminary feasibility study and laboratory demonstration to evaluate the sensitivity of the electro-thermal method by detecting artificial discontinuities in stainless steel test plates [2]. An experimental system, assembled from available laboratory components, was used to conduct this demonstration study. The plates used as test specimens were $2 \times 4 \times 0.2$ inch $(5 \times 10 \times 0.5 \mathrm{~cm})$, had smooth surfaces, and were made of Type 304 stainless steel. Each plate contained one 0.005 inch $(0.013 \mathrm{~cm})$ wide electrical discharge machined (EDM) notch, and a series of 13 plates were 
used to evaluate the response to notches with different lengths and depths. :igure 6 shows a close-up of one of the plate specimens and the electrode configuration. Laboratory tests demonstrated that this experimental sys:em was capable of detecting notches cut into either the front or back surfaces of the test plates.

lixperiments were conducted using different combinations of electrode coniact and notch placement to evaluate the sensitivity to surface and subsuriace discontinuities. Figure 7 illustrates the response obtained from three different sized notches on the front surface of the plates (i.e. side facing the infrared camera). The dark regions are low temperature zones corresponding to areas with low electrical current flow, and the bright lines are clue to a type of cavity effect. The cavity effect occurs because the infrared camera "sees" the notch as a small, high emissivity area. Notice that a notch as small as 0.06 inch $(0.16 \mathrm{~cm})$ long $\times 0.06(0.16 \mathrm{~cm})$ deep was detected.

Figure 8 illustrates the response that was obtained from three different sized notches that were located on the back surface of the plates (i.e. side i.way from the camera). This figure illustrates typical sensitivities to subsurface discontinuities; or to discontinuities on the inner surface of a component when an examination is performed from the outer (accessible) surface. Although the response data are not included in the illustrations, our laboratory system was able to detect notches on the back surface as small as $(1.03$ inch $(0.80 \mathrm{~cm})$ deep $\times 0.50$ inch $(1.28 \mathrm{~cm})$ long, and also 0.12 inch $(0.32$ $\mathrm{cm})$ deep $\times 0.12(0.32 \mathrm{~cm})$ long when the electrical current was applied only to the front surfaces of the test plates. In other words, we could detect $1 / 8$ inch long notches that penetrated about $60 \%$ through the plate, and $1 / 2$ inch long notches that penetrated only about $15 \%$ through the plate.

The results obtained during this study have shown that the significant infrared (surface temperature) features of the electro-thermal indications from front surface notches are two adjacent dark (low temperature) regions. The infrared patterns obtained from back surface and subsurface notches is a single bright (high temperature) region. Thus, qualitative interpretation of the results from an electro-thermal examination appears to be relatively straightforward.

Our investigation provided a conclusive demonstration of the potential sensitivity of this method for examining stainless steel components, and indicated 
that the method offers potential for inservice inspection applications. Evaluation of the electro-thermal method on components with rough surfaces (such a: welds) was not performed during this study, but future work is planned in this area using a high frequency current source to limit the current penetration depth and minimize the effect of surface roughness.

\section{Eldy Current Methods for In-Situ Examination of Heat Exchanger Tubes}

S.ingle and multiple frequency eddy current (ET) techniques have been evaluated for applicability to inservice inspection of the tubes in sodium/sodium heat exchangers. This investigation was conducted in two phases using laboratory ecjuipment, mock-up fixtures to simulate the configuration of tubes in the FFTF intermediate heat exchangers (IHX's), and test samples cut from typical IHX tubes.

The Phase I tests were conducted using a four-tube mock-up that had been immersed in hot sodium (Figure 9). Drilled holes and EDM notches were used to simulate defects in the tube walls, and baseline eddy current examinations were conducted before the tubes were exposed to sodium. After exposure for atiout 30 hours at $1100^{\circ} \mathrm{F}$, the sodium was drained and the tubes were periodically reexamined during removal of residual sodium deposits using a sequential cleaning process. During many of the Phase II tests, solder was used to simulicte sodium deposits on the tubes. The experimental arrangement used during these studies is schematically depicted in Figure 10.

Or the basis of the initial investigations, it was concluded that conventional, single frequency, eddy current equipment (operating at approximately $100 \mathrm{kHz}$ ) generally provides an effective examination on Type 304 stainless steel tubes trat are 0.875 inch $00 \times 0.049$ inch wall thickness and have not been exposed tc sodium [3]. The conventional single frequency method did not provide an effective examination on sodium contaminated tubing because sodium deposits produced signals that could interfere with the detection of significant disccntinuities. If the sodium can be thoroughiy removed from the inner surfaces of the tubes and detection of outer surface discontinuities is not intended, a conventional single frequency test (operating at about $1 \mathrm{MHz}$ ) can provide an effective examination for inner surface discontinuities.

The second phase of this program involved an investigation of multi-frequency (rulti-parameter) techniques in search of a successful method for inservice examination of sodium-contaminated IHX tubing [4]. A four-frequency laboratcry system was assembled and evaluated. It was found that this system could 
detect discontinuities on the outer tube surfaces while effectively discriminating against the interfering signals caused by probe motion, tube supports, and residual sodium on the outer surfaces of the tubes. However, we were not able to discriminate against the large signals which resulted from residual sodium on the inner surfaces of the tubes, because these signals exhibited characteristics that were inseparable from the signals from discontinuities on the inner tube surfaces. In addition, when sodium was retained within a discontinuity on either tube surface, its effect was to reduce or otherwise modify the shape of the signal from a discontinuity alone.

Under Sodium Viewing and Ranging

A prototype Under-Sodium Viewing and Ranging (USV) system has been developed and demonstrated as a possible inservice inspection method [5]. Special ultrasonic transducers were developed for use with the system to produce pseudo 3-D pictures of objects immersed in $16 \mathrm{ft}$. $(4.9 \mathrm{~m})$ of liquid sodium. Such a system could eliminate the need to drain the sodium coolant for certain in-vessel inspections, thereby minimizing reactor downtime which can cost more than $\$ 200,000$ per day in lost revenue for a nuclear power plant. The USV system operates in two modes: viewing and ranging.

The viewing mode can produce high resolution pictures of objects, and could be applied to inspect critical areas such as the surfaces of certain welds that are immersed in sodium. This technique employs a HEDL-patented Iso-Scan technique which permits the operator to visualize objects in three dimensions, as shown in Figure 11. The dimensions of objects may then be measured directly from the viewing screen through the use of conventional B and C scan presentations, which correspond to elevation and plan views, respectively. It is important to nota that the viewing perspectives are changed electronically by adjusting two controls on the electronic coordinate transformation module. Thus, only a single series of scans above the object is required to store data in memory. The object can then be viewed at will from the top, sides, or obliquely, and an optimum vieving perspective can be selected without rescanning the object.

For inservice weld inspections, the present $C$-scan capability should be adequate to perform an effective surface examination. However, if the difficulties that are currently encountered during the examination of austenitic welds (e.g. spuriou: signals) can be overcome, volumetric weld examinations under sodium will 
then be possible with a USV system. Furthermore, the Iso-Scan display techniques could be of significant benefit in determining the size and orientation of defects.

Viewing is accomplished with the present USV system by rotating and indexing a scanner arm that contains a total of 34 transducers. The scanner arm is positioned above the object to generate eleven $5 \mathrm{MHz}$ ultrasonic beams that are directed vertically downward. Typical viewing distances are 2 to 12 inches $(5-30 \mathrm{~cm})$, although lower-resolution pictures can be formed at greater distances.

Objects in sodium can be precisely located at distances up to $16 \mathrm{ft} .(4.9 \mathrm{~m})$ by operating the system in the ranging mode. This mode employs twenty-three $2 \mathrm{MHz}$ transducers that are mounted on the top, sides, and end of the scanner arm to produce range and azimuth data. Ranging data are displayed on a memory oscilloscope using a "radar" type of presentation. This mode suggests additional inservice inspection capabilities such as monitoring changes in the position of invessel mechanisms and assisting in the location and retrieval of foreign objects.

The HEDL development program resulted in the assembly and successful liquid sodium testing of a prototype USV system designed for possible use in the FFTF. A closeup view of the scanner arm that was used is shown in Figure 12. Testing was performed in a 40,000 gallon $\left(151 \mathrm{~m}^{3}\right)$ sodium test facility which contained a full-scale model of one-third of the FFTF core and related reactor vessel internals. Figure 13 shows a conventional photograph (plan view) of the simulated FFTF core in the test facility prior to sodium fill, and a low-resolution USV image of the same area, for comparison. Higher resolution pictures permitted identification of core subassemblies by forming images of coded notches and small diameter indentations placed on the top surfaces of fuel subassembly handling sockets as shown. in Figure 14 . Features as small as 0.06 inch $(1.5 \mathrm{~mm})$ are resolved in this picture.

Significant improvements in resolution are possible through the use of image enhancement techniques. In addition, the scanner arm could accommodate design features to imorove the mechanical stability and thereby reduce picture blurrins. 


\section{CONCLUSIONS}

In conclusion, highlights of HEDL development activities in four separate areas hive been described in this paper. Experimental results obtained in each of these were discussed along with comments on potential applicability for future inservice inspection of LMFBR's. This paper described preliminary development work only, since firm requirements for inservice inspection of LMFBR's have not yet been established.

The problems that have been encountered during ultrasonic examination of austenitic stainless steel welds are significant and difficult, but we are confident that the effectiveness of this method can be improved. Future work or this program will emphasize investigations of electronic signal enhancement processes and computerized noise discrimination techniques, in conjunction with the development and evaluation of techniques, equipment, and procedures that are tailored to the examination of austenitic stainless steel weldments. Initial experimental results provided a valid demonstration of the intrinsic sensitivity of the electro-thermal methed for examining stainless steal crononents. These investigations also indicated that this method offers potential for inservice inspection applications.

Iri-situ examination of the tubes in sodium/sodium heat exchangers using eddy current equipment appears feasible if the sodium can be thoroughly removed from the inner surfaces of the tubes. Outer surface defect signals could be detected in spite of the interference from nondefect signals, although residual scidium on the inner tube surfaces tended to obscure the response from inner surface discontinuities. In addition, sodium in discontinuities on either tcbe surface altered the characteristics of the signals from discontinuities. A prototype under-sodium viewing and ranging system has been assembled and successfully demonstrated in a test facility operating at typical LMFBR shutdown temperatures. Such a system offers potential for minimizing the downtime required for in-vessel maintenance of LMFBR's. Tests of the system that was designed for FFTF use demonstrated that functions such as weld surface examination might be performed using an in-reactor scanning device. 


\section{ACKNOWLEDGEMENTS}

The development projects described herein were conducted by my colleagues at the Hanford Engineering Development Laboratory, and I welcome this opportunity to recognize their efforts and to thank them for their assistance during the preparation of this paper. They are:

Steve Mech and Bob Peterson: Ultrasonics

Russ Brown and Clarence Wandling: Eddy Currents

Don Green and Jim Hassberger: Electro-Therma?

Cliff Day and Neil Hoitink: Under-Sodium Viewing

A sjecial word of thanks to my secretary, Jean Young, for her conscientious effiorts during the preparation of this manuscript.

\section{REF $=$ RENCES}

[1] R. 0. Peterson, J. C. Spanner, and S. J. Mech, Development of UItrasonic Methods for Examining Stainless Steel Welds - Interim Progress Report, HEDL-TME-75-134, Hanford Engineering Development Laboratory, Richland, Washington (November 1975).

[2] D. R. Green and J. A. Hassberger, Feasibility Study on Infrared ElectroThermal NDE of Stainless Steel, HEDL-TME-75-133, Hanford Engineering Development Laboratory, Richland, Washington (November 1975).

[3] R. L. Brown and C. R. Wandling, A Feasibility Study on In-Service Inspection of Sodium-Contaminated IHX Tubing With Single Frequency Eddy Current NDT Equipment, HEDL-TME-72-152, Hanford Engineering Development Laboratory, Richland, Washington (December 1972).

[4] R. L. Brown, In-Service Examination of IHX Tubing With Eddy Current NDT Equipment, HEDL-TME-75-29, Hanford Engineering Development Laboratory, Richland, Washington (May 1975).

[5] N. C. Noitink and C. K. Day, Under-Sodium Viewing System Development for FFTF, HEDL-TME-75-103, Hanford Engineering Development Laboratory, RichTand, Washington (December 1975). 


\section{CAPTIONS FOR ILLUSTRATIONS}

FIGURE 1. Photograph Showing Typical Weld Samples Employed During Ultrasonic Investigation.

FIGURE 2. Schlieren Images Comparing 2.25 MHz U7trasonic Beam Transmitted Through Base (Parent) i.letal and Weld Metal.

F]GURE 3. Montage of Photomicrographs Taken at Noise Site 1 in Weld Sample WS-27-2.

FIGURE 4. Montage of Photomicrographs Taken at Noise Site 2 in Weld Sample WS $-27-2$.

FJGURE 5. Montage of Photomicrographs Taken at Site DI in Weld Sample WS-12.

F]GURE 6. Closeup of Test Specimen and Holding Fixture (Electrodes) Used to Demonstrate the Electro-Thermal Method.

F]GURE 7. Electro-Thermal Indications from EDM Notches on the Front Surface of Test Specimens.

F]GURE 8. Electro-Thermal Indications from EDM Notches on the Back Surface of Test Specimens.

F]GURE 9. Four-Tube Mock-Up Used to Investigate Sodium Effects on Eddy Current Examination.

FJGURE 10. Schematic Arrangement of Equipment Used to Investigate Sodium Effects on Eddy Current Examination.

FIGURE 11. Iso-Scan Technique Used to Vary Viewing Perspective of USV Images.

FIGURE 12. Closeup View of Scanner Arm for Under-Sodium Viewing System.

FIGURE 13. Photograph Showing Top of FFTF Core Mock-Up (Left), Compared With an Image of Same Area Obtained With the Under-Sodium Viewing System (Right).

F...GURE 14. Photograph Showing the Top Surface of a Fuel Subassembly Handling Socket (Left), Compared with an USV Image of the Same Surface (Right). (Note the coded notches and indentations that are used to identify the subassemblies.) 


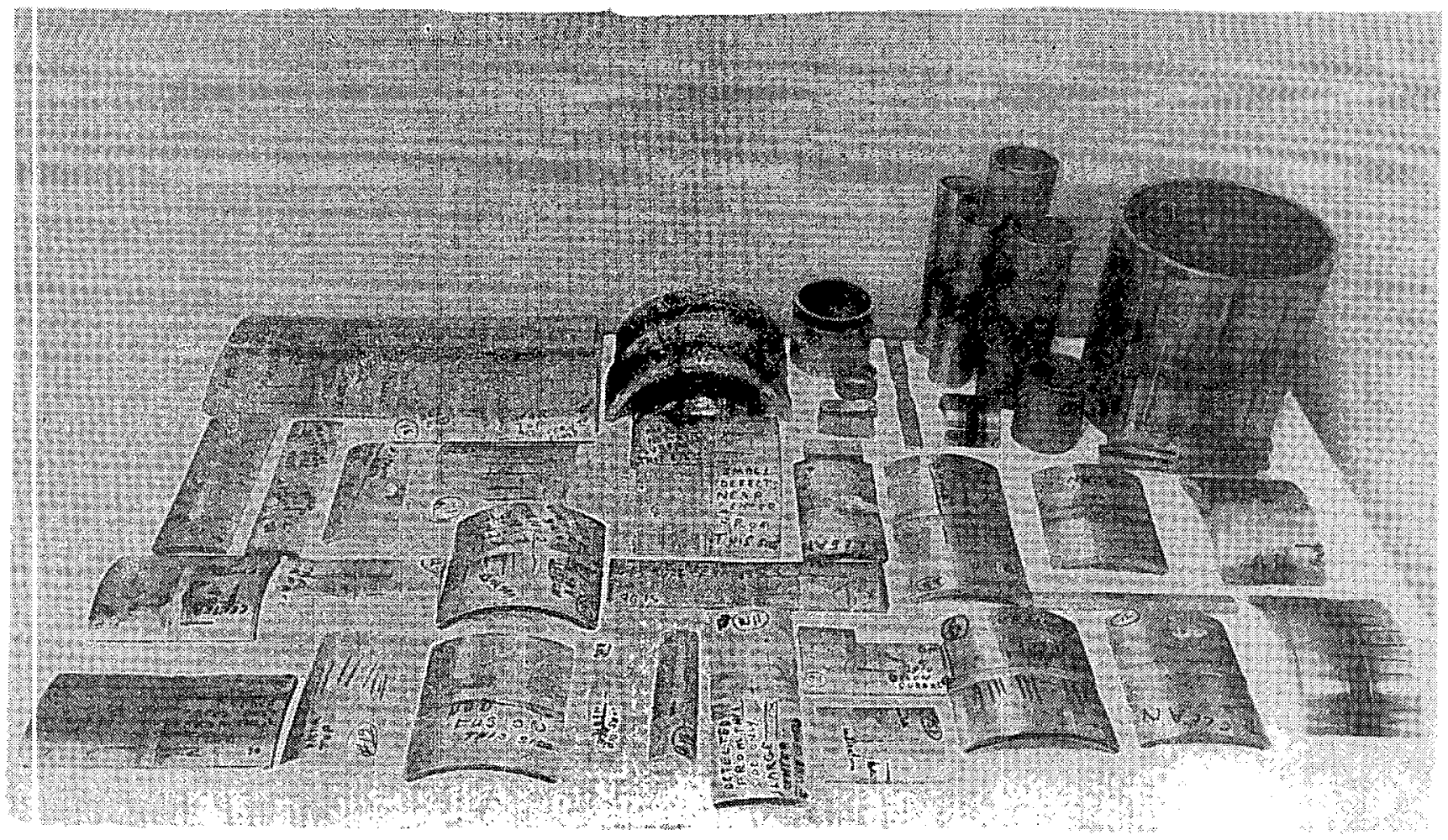

Froure 1. Photograph Showing Typical weid Samples Employed during Utrasonto investigation.
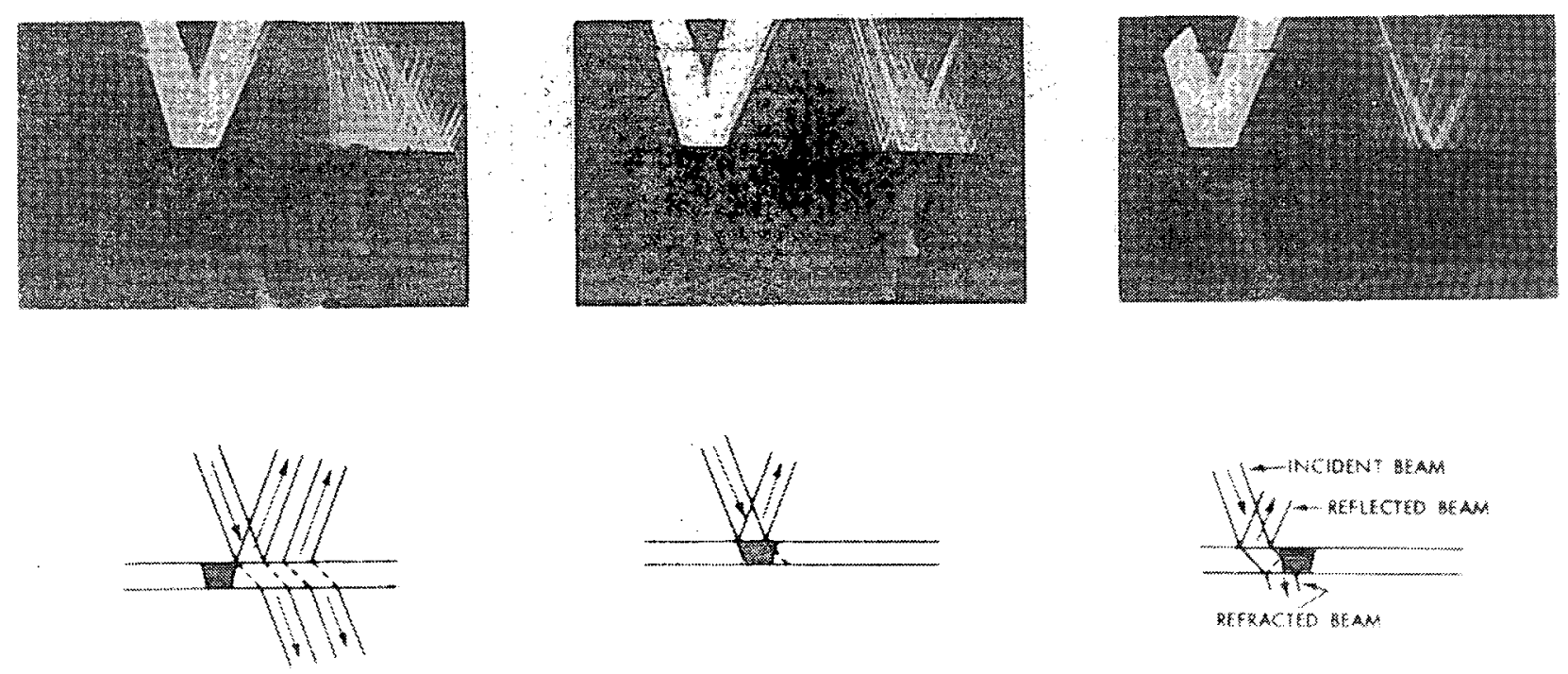

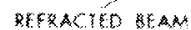

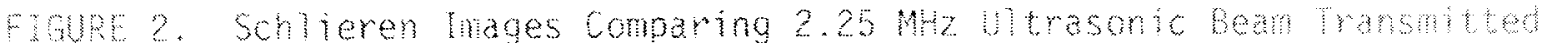
Through base (Parent) Metal and veltheta? 


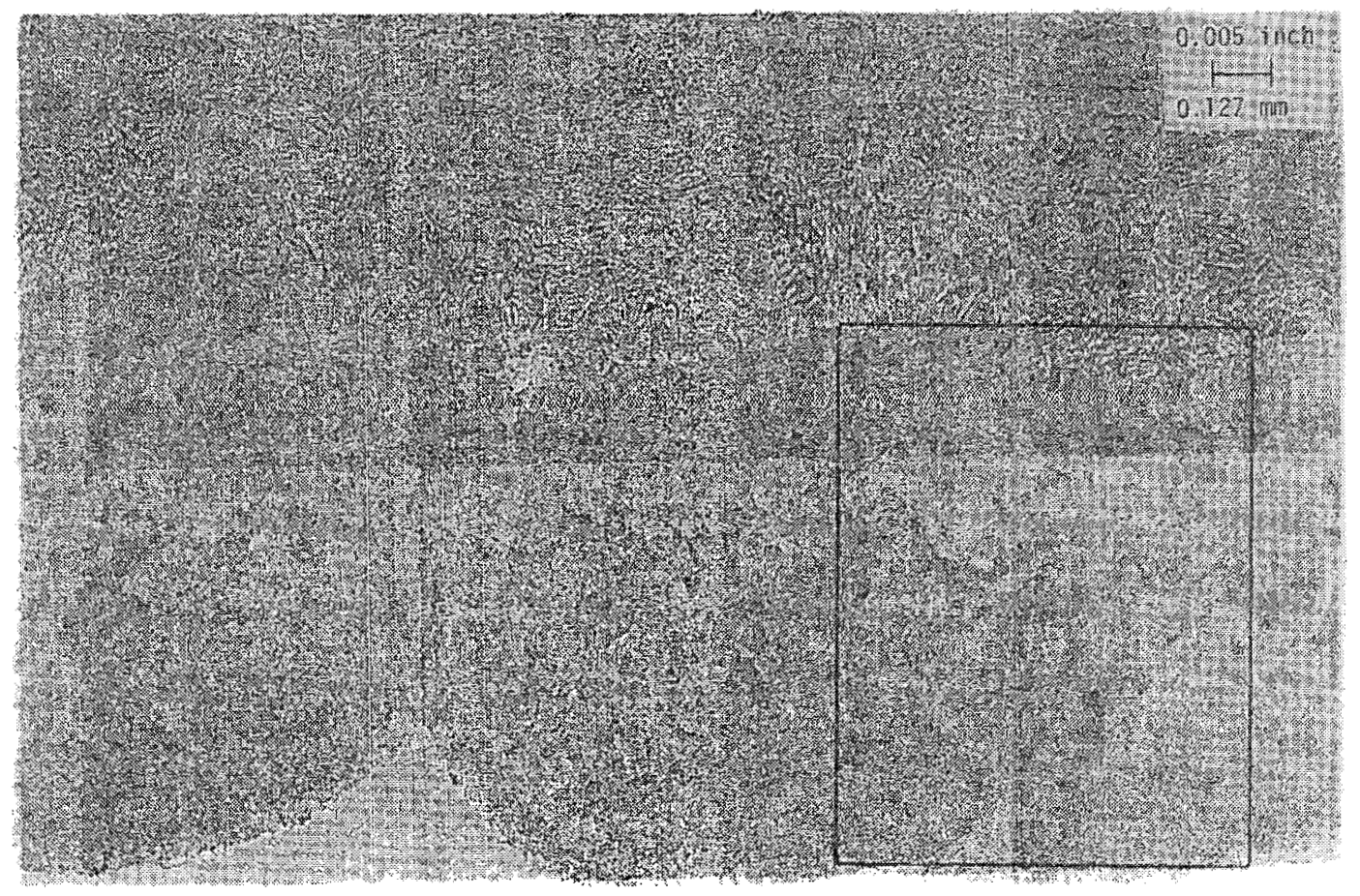

FIGURE 3. Montage of Photomicrographs Taken at Noise Stte 1 in Weld Sample WS-27-2.

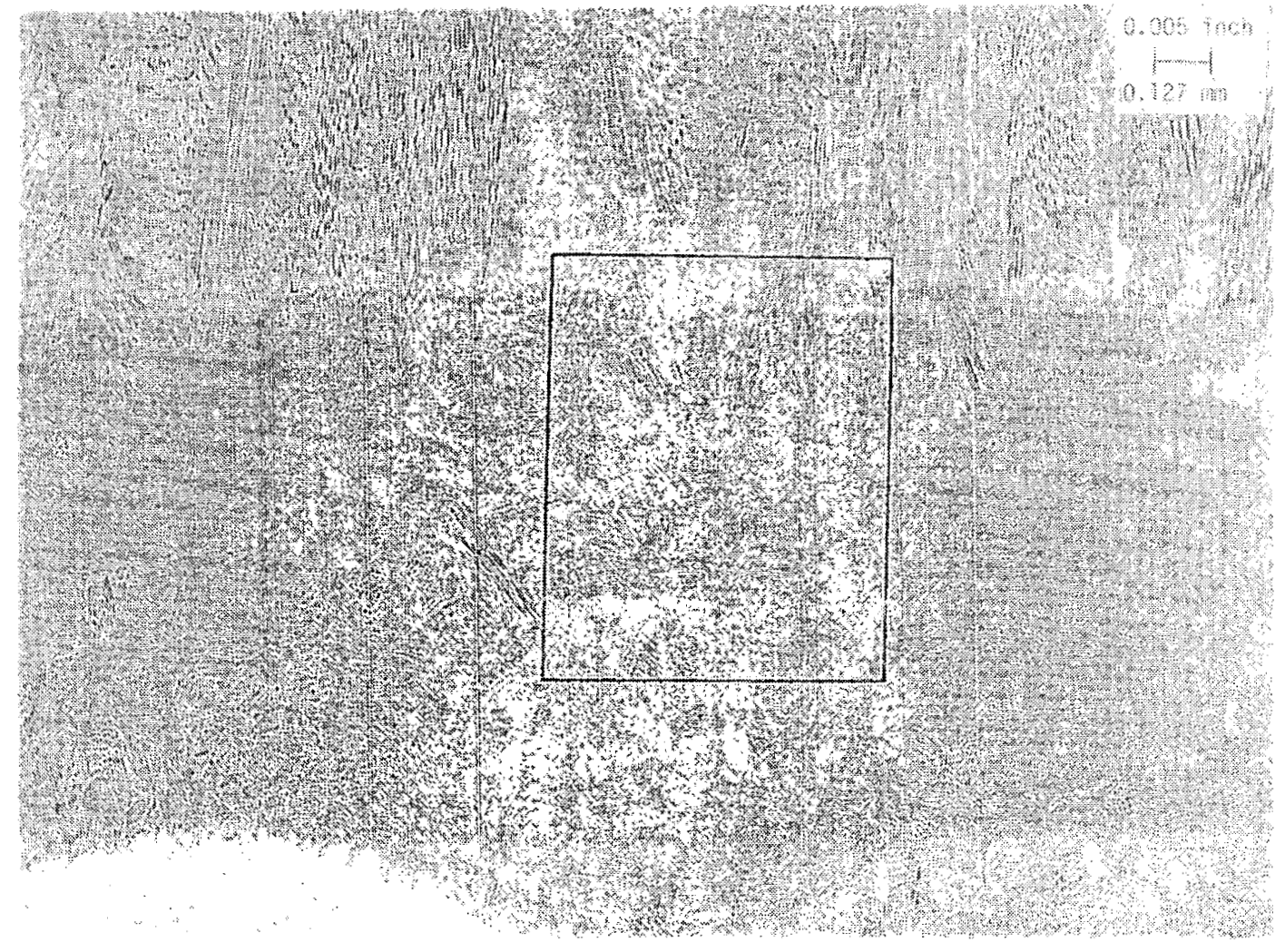

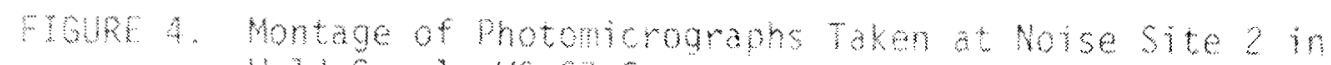
heid sample $45-27-2$. 


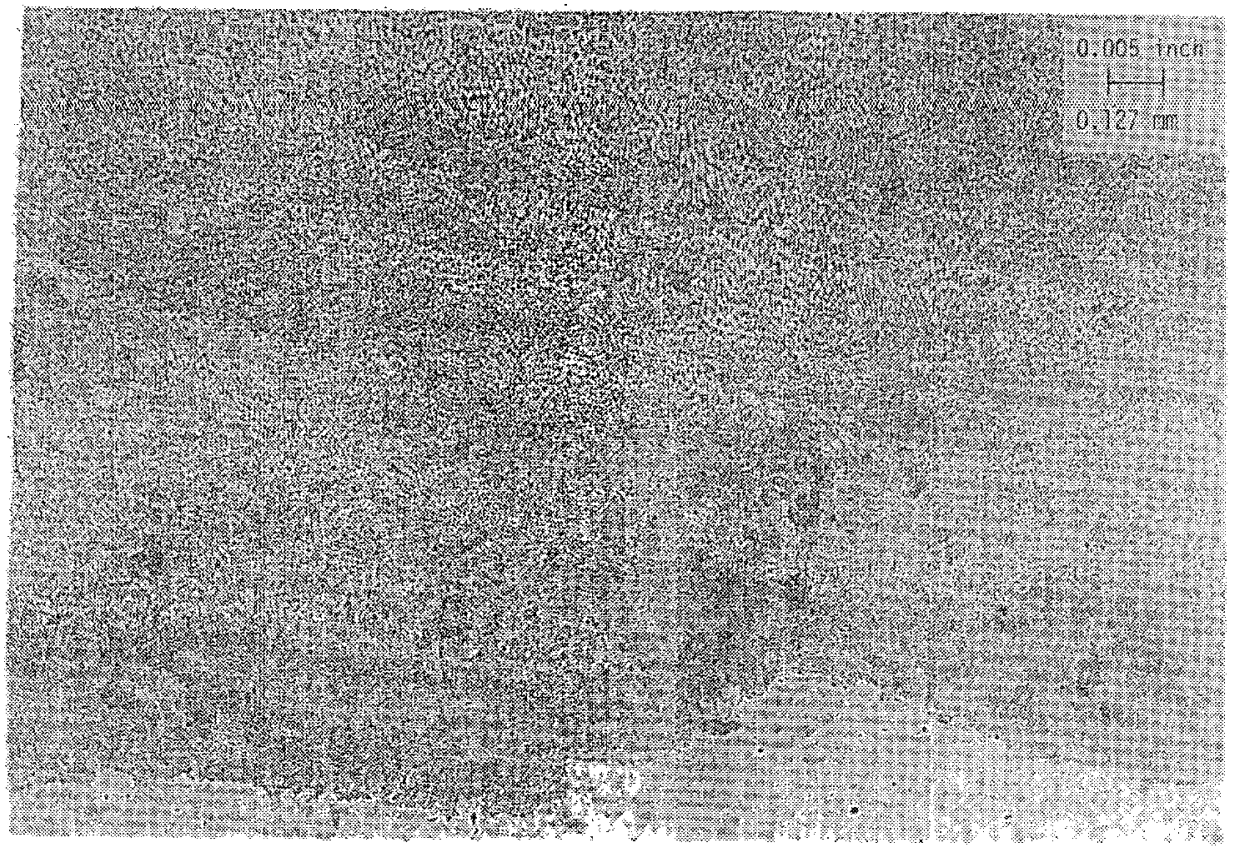

FIGURE 5. Montage of Photomicrographs Taken at Site of in Weld Sample WS-12.

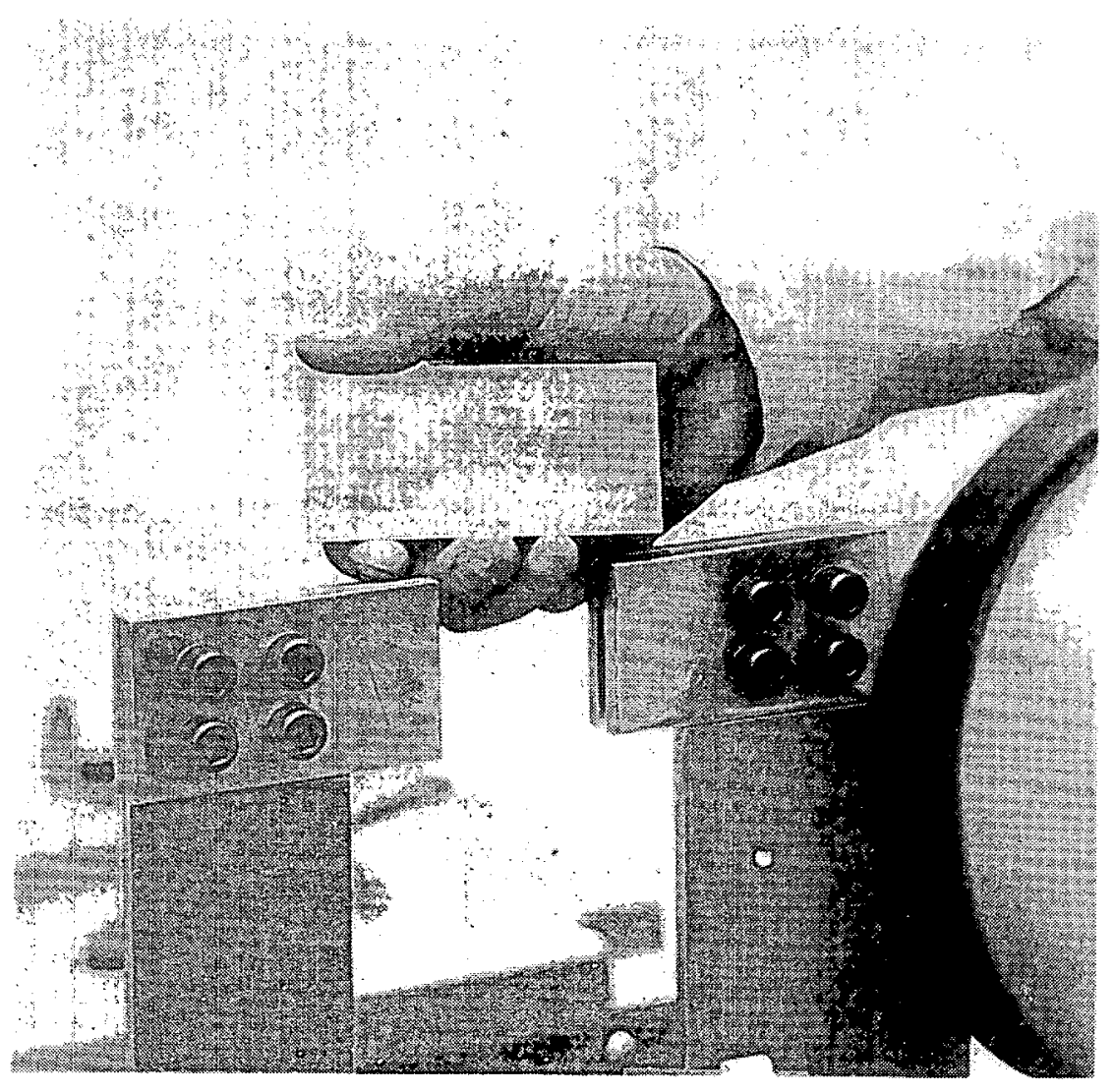

Foure 6. Closeup of Test Specimen and holding fixture (Mectrodes) Used to Demonstrate the floctrom Themol Method 


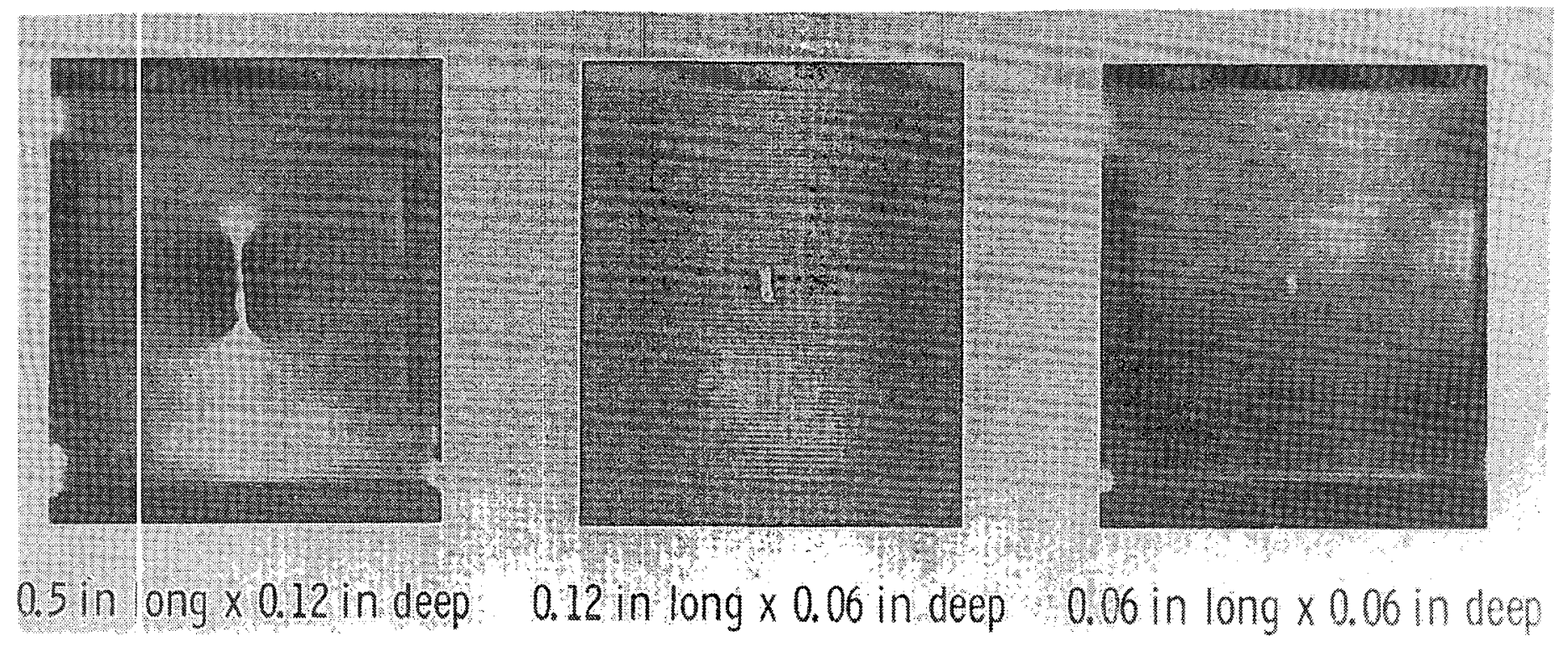

GIUURE 7. Electro-Therma? Indications from EOM Notches on the Front Surface of Test Specimens.

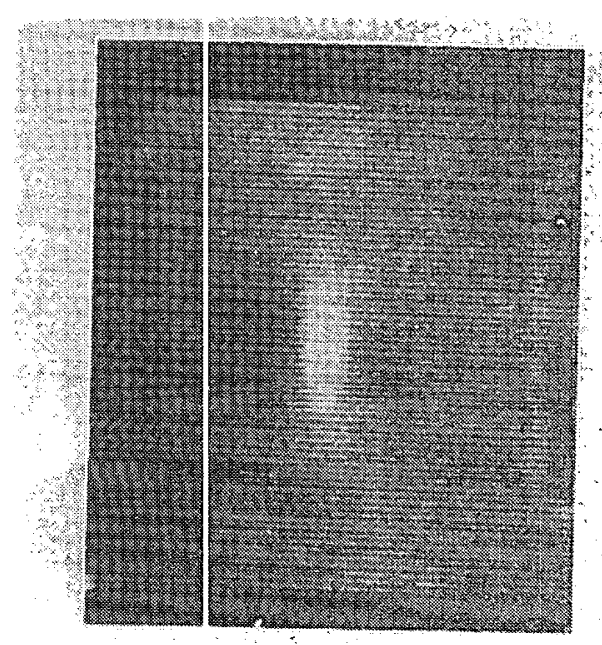

0.5 in long $\times 0.12$ in deep

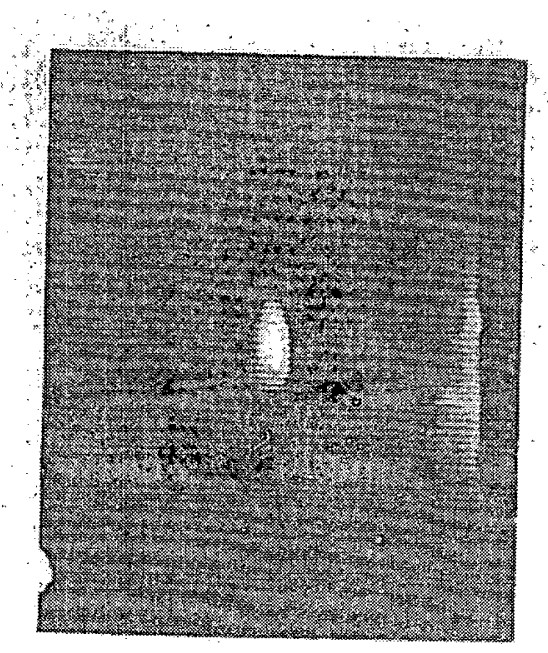

0.25 in long $x 0.12$ in deep

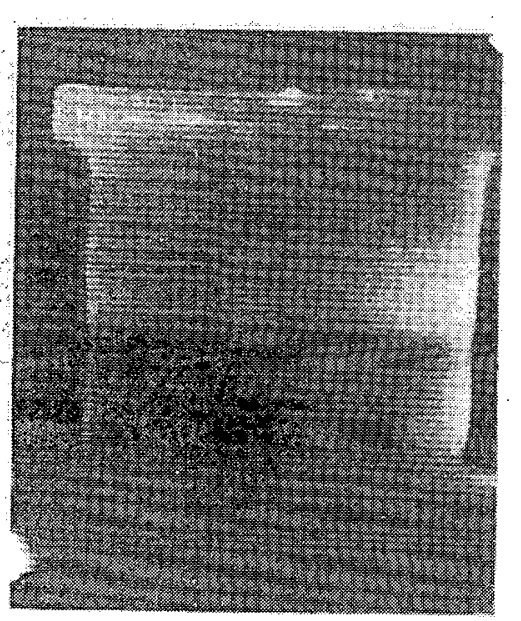

0.5 in long $x 0.03$ in deep

FGRR: 8. Electro-Thermal Indications from Wu Notches on whe back surface of Test Specimens. 


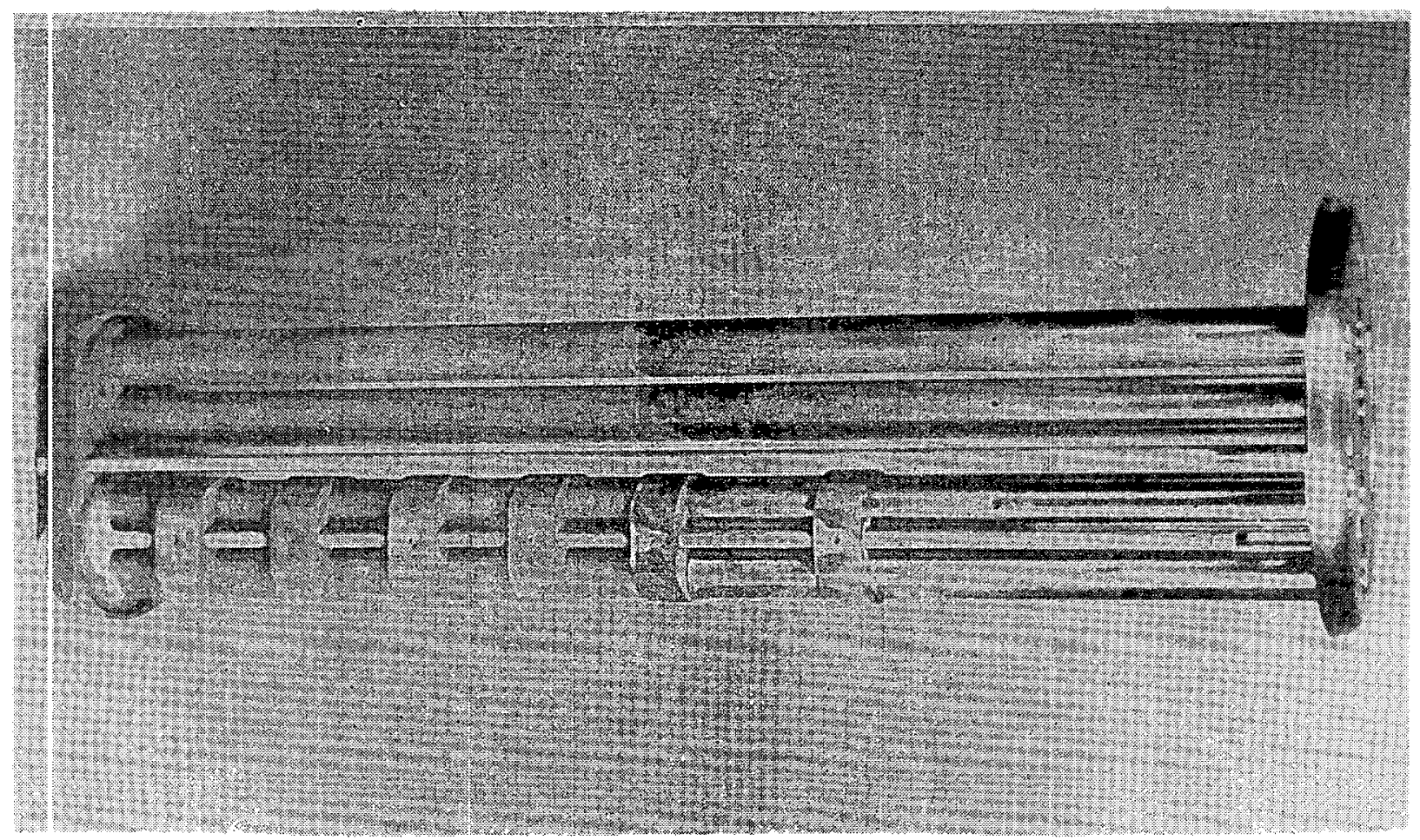

FIGURE 9. Four-Tube Mock-Up Used to Investigate Sodium Effects on Eddy Current Examination.

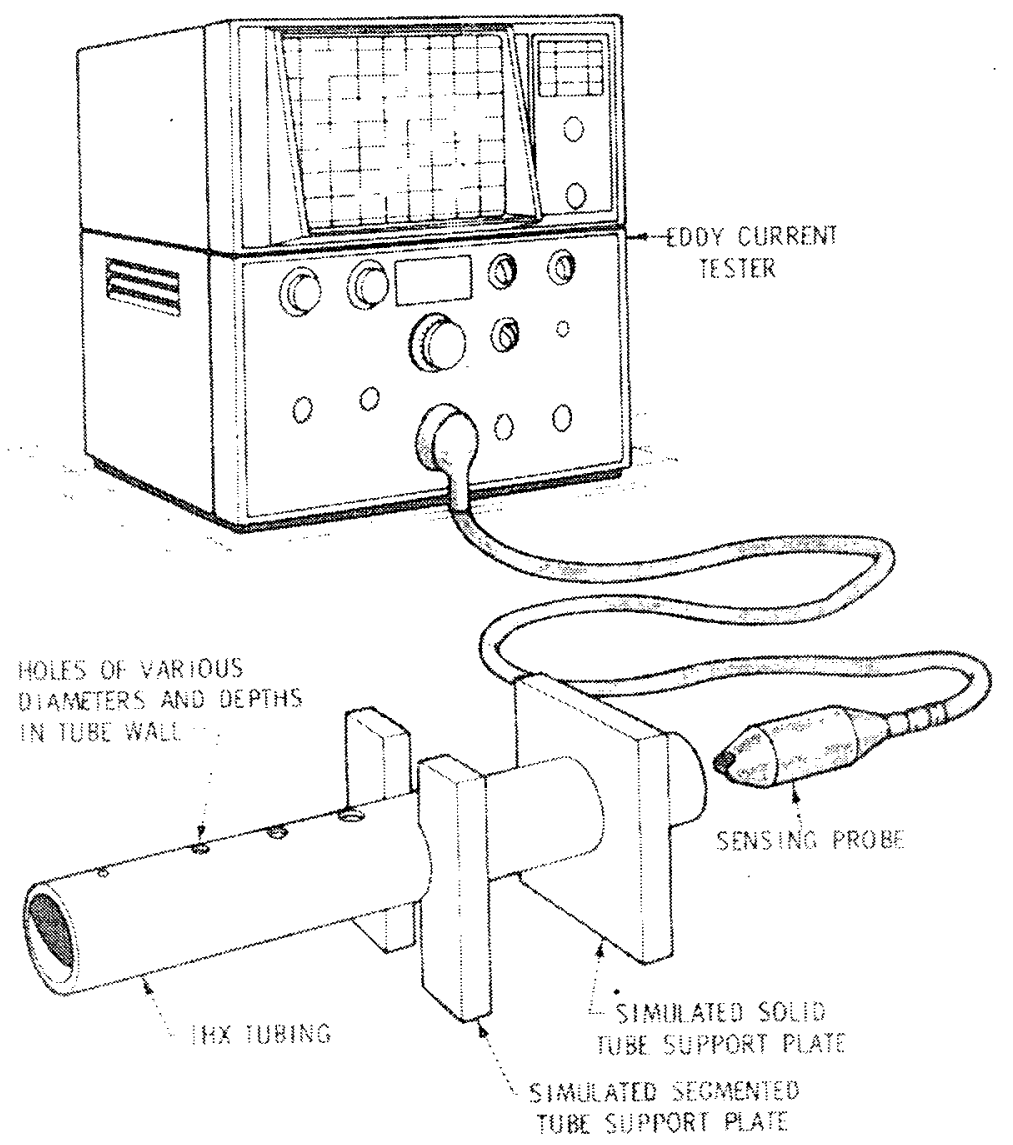

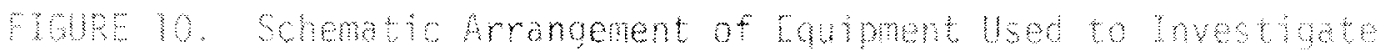
sodum Frects on Eddy Current Eamination. 


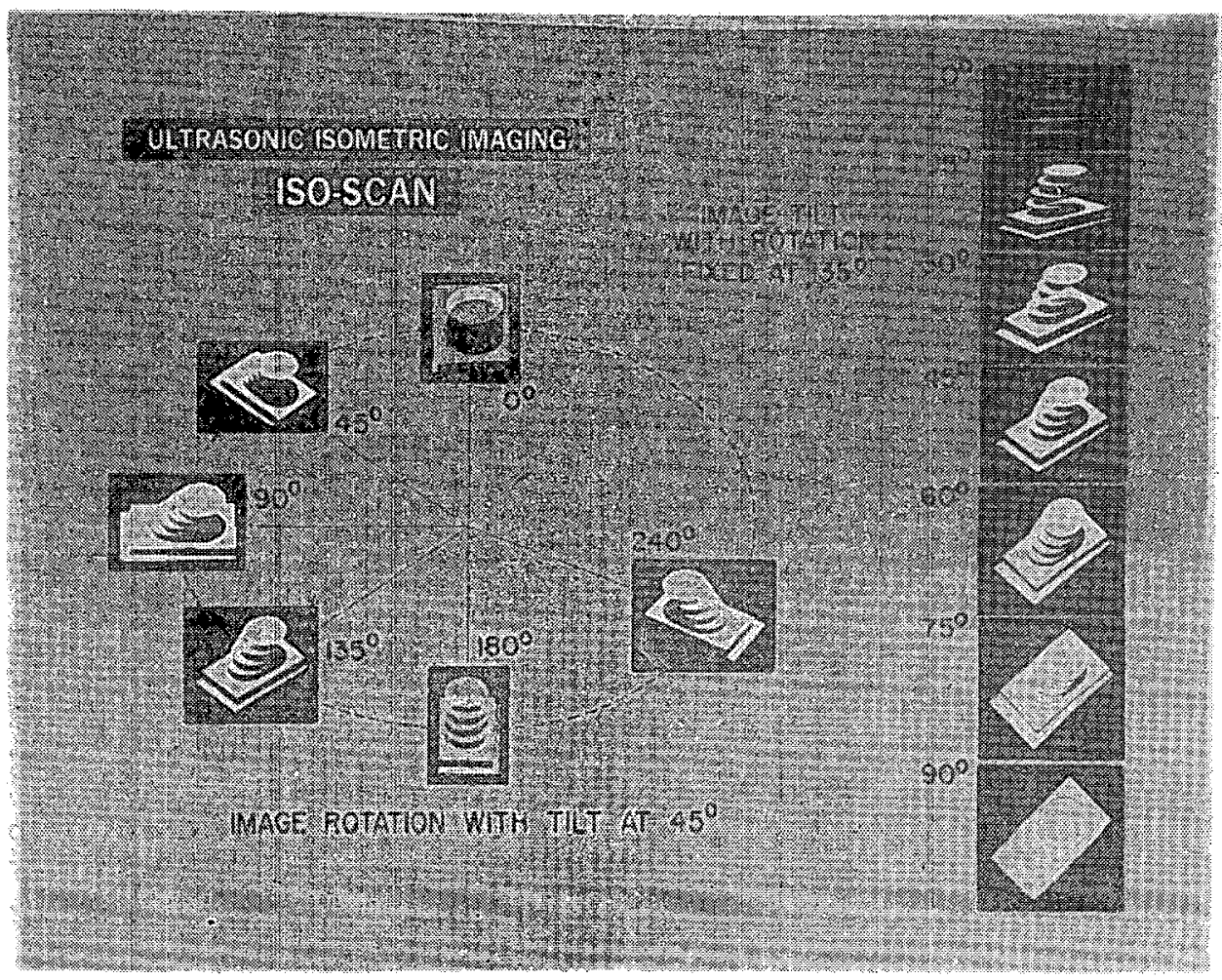

FIGURE 11. Iso-Scan Technique Used to Vary Viewing Perspective of USV Images.

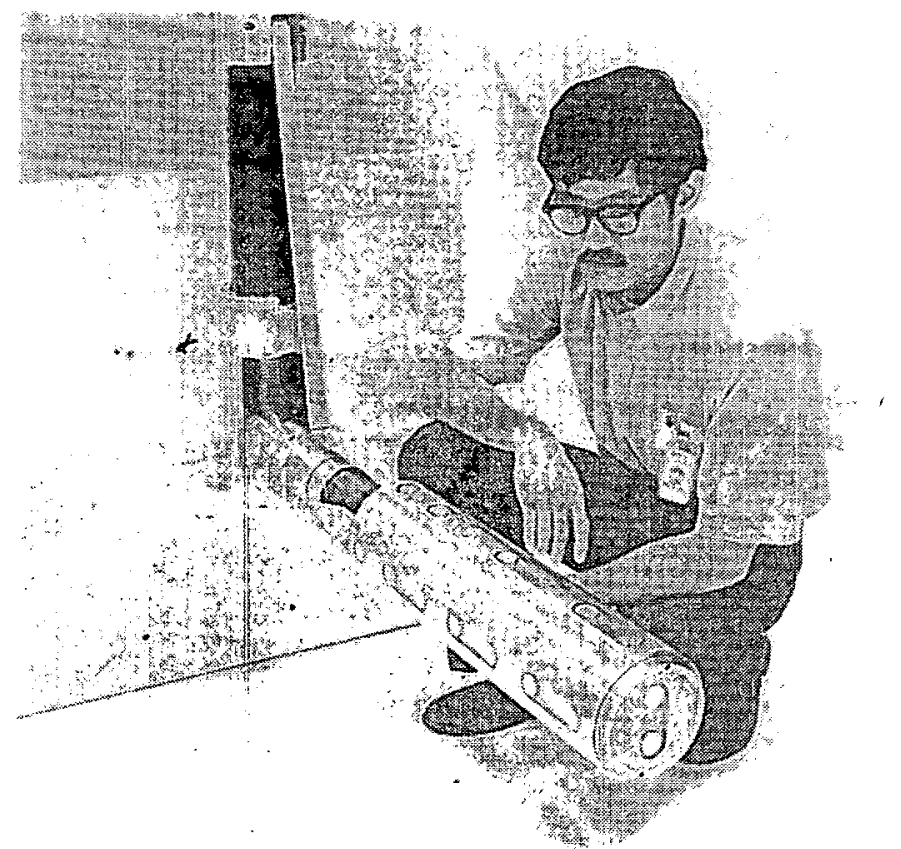

"IGURE 12. Closeup View of Scanner Arm for Under-Sodium Vhenth Systom. 

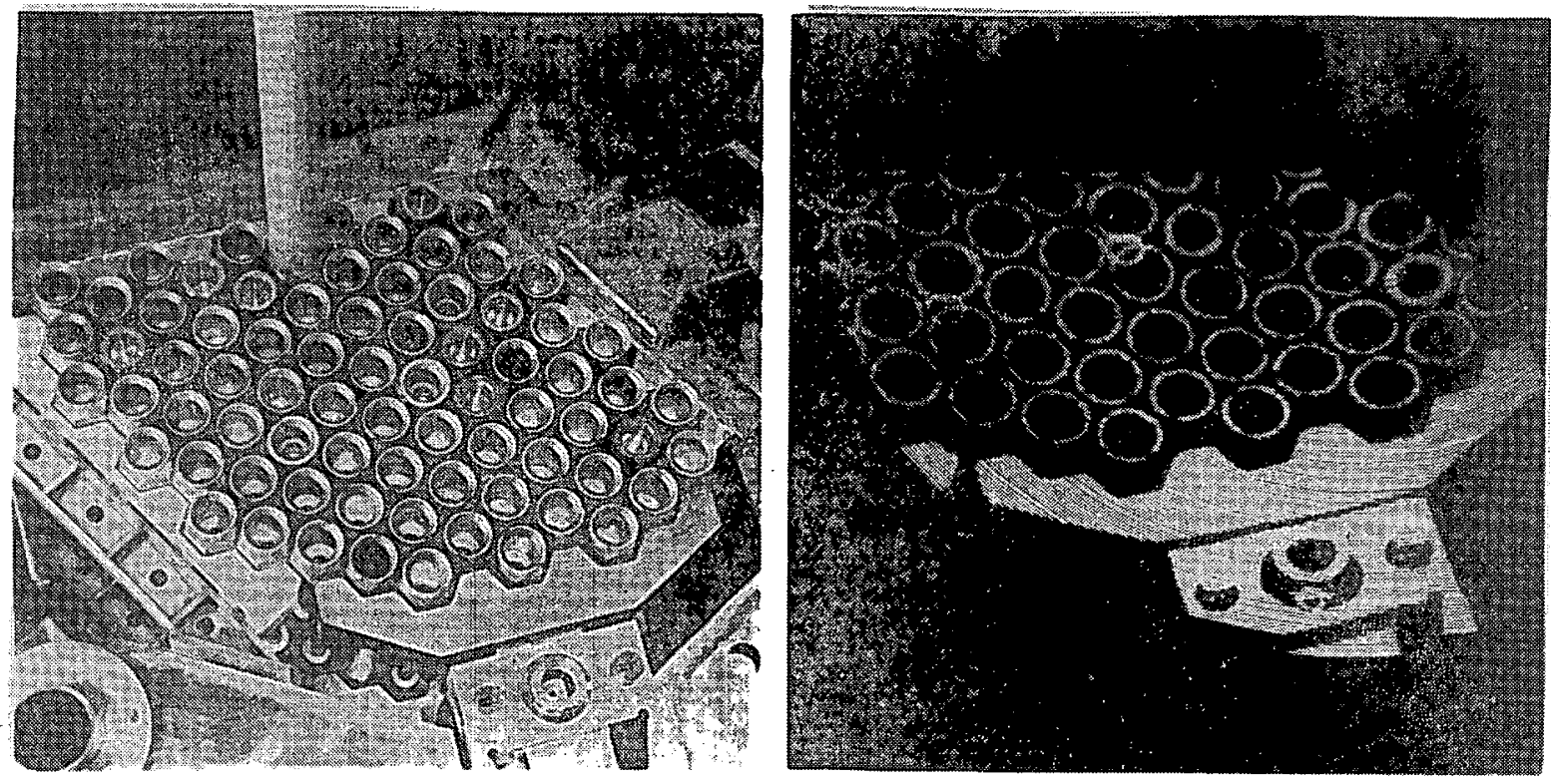

FIGURE 13. Photograph Showing Top of FFTF Core Mock-Up (Left), Compared with an Image of Same Area Obtained With the UnderSodium Viewing System (Right).
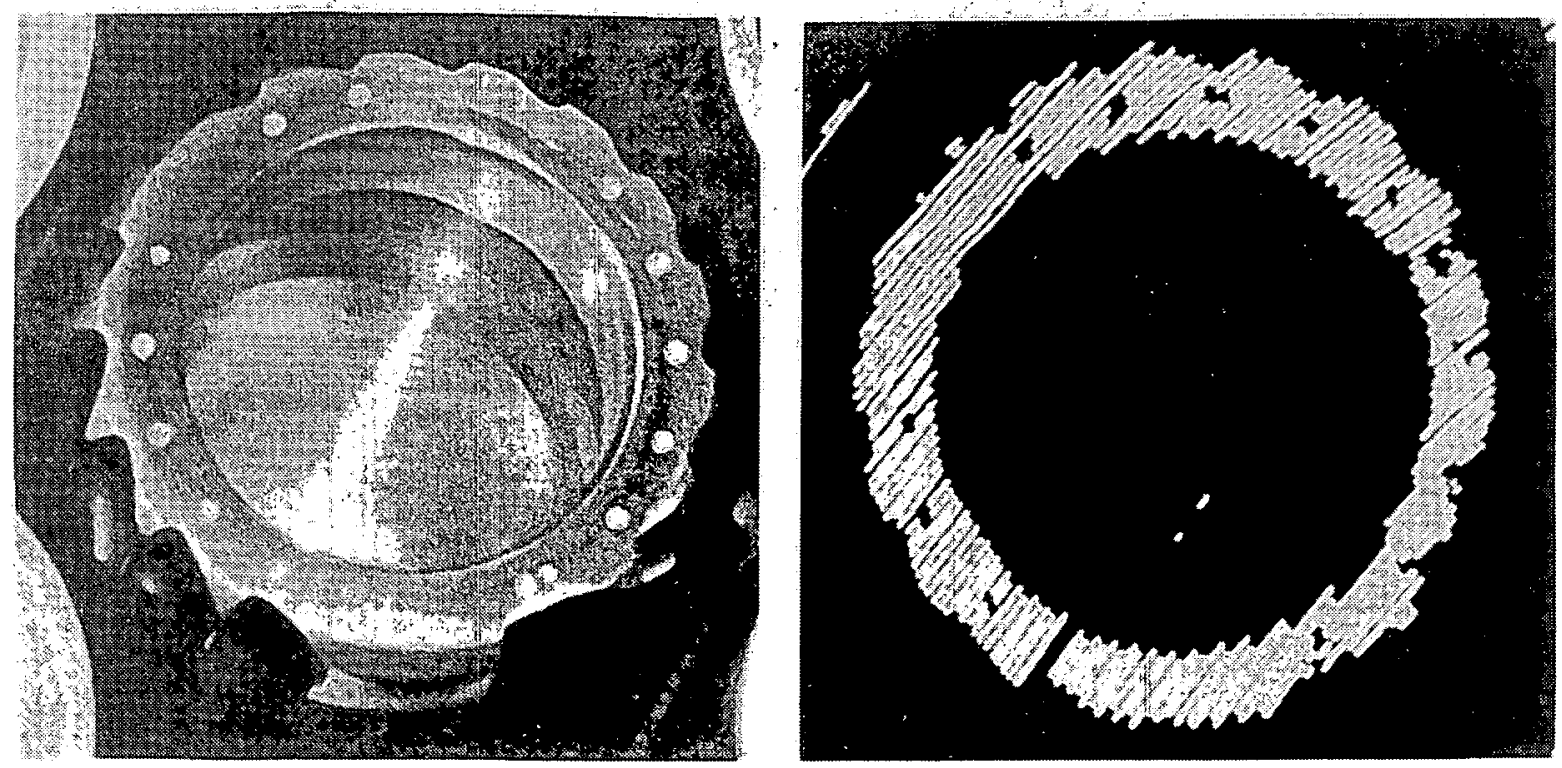

FIGURE 14. Photograph Showing the Top Surface of a Fuel Subassenty Handing socket (Left), compared with un US Image of the Same Surface (Right). (Note the coded notches and indenm tetions thet are used to identify the subassentles. 